of the Aplacophora and of the Chitons. In Part $11 \mathrm{f}$ (Thalassobionta and thalassophile Myriapoda), Dr. Otto Schubart describes the maritime and submaritime Myriapods. There are a large number of the Aplacophora in this region, but although their anatomy is fairly well known, there is a lamentable gap in our knowledge of their development and life histories, the chief work on these having been done with species from elsewhere. The same may be said of the Placophora, although more is known of this group and the eggs of a few of our common forms have been seen. All the species are very clearly described and figured with details of the plates, so that identification should be easy, and the anatomy, biology, and distribution are fully discussed.

The large number of myriapods which are more or less marine is surprising. Most of these live on the shore between or above tidemarks, and they belong to several different groups. Dr. Schubart gives a very interesting account of these, especially with regard to their biology. Some of them can remain alive under water many days, although not so long in salt water as in fresh, and in no case is it a natural habitat. Damp, salty situations are by no means avoided, the chief localities being rocky and stony shores. The internal anatomy is barely touched upon, but much space is given to the distribution and ecology of the species. Most of the illustrations are original photographs or line drawings.

A School Geometry. By A. Walker and G. P. McNicol. Part 1 (Books I.-III.). Pp. viii +256 . 3s. 6d. Part 2 (Books IV.-VII.). Pp. vi +251 . 492. 3s. 6d. Part 2, Section 1 (Books IV.-V.). Pp. vi +251-352. 2s. Part 2, Section 2 (Books VI.-VII.). Pp. vi +351-480. 2s. (London, New York and Toronto: Longmans, Green and Co., Ltd., 1930.)

THIs book is an improved version of the type of text-book on elementary geometry that began to appear about thirty years ago. It is carefully written and the supply of exercises is better than in some of the older books, but there is the traditional emphasis on 'bookwork' which seems somewhat out-of-date. When examination papers in geometry consisted half of Euclid's propositions and half of riders demanding some real geometrical power, all that teachers could hope to do for their feebler pupils was to get them to understand enough about the subject to write out the propositions intelligently. Nowadays, what is demanded is some power of independent thought sufficient to answer simple questions which, though they can scarcely be called riders in the old sense, are definitely not bookwork. It is found possible to satisfy this demand save in very exceptional cases, and it can scarcely be doubted that the modern training is the more valuable.

The process of learning propositions in a definite sequence, whether Euclid's or some other, comes nowadays later in the geometry course, and is not generally regarded as the matter of primary importance. Therefore a text-book arranged like this one, on traditional lines, is not probably the most convenient, especially for an inexperienced teacher who is perhaps doubtful about how the reading should be arranged.

The printing and general arrangement of the book reflect the greatest credit on the printers and publishers.

A. R.

\section{Leçons sur les systèmes d'équations aux dérivées} partielles. Par Prof. Maurice Janet. (Cahiers scientifiques, Fascicule 4.) Pp. viii +125 . (Paris : Gauthier-Villars et Cie, 1929.) 30 francs.

PROF. M. JANET has produced a valuable contribution to the analytical theory of partial differential equations. It opens with a clearly written introduction in which are discussed the chief problems arising out of the general theory to be considered. Then follow two chapters on "Calcul inverse de la dérivation", existence theorems, and the linear partial equation of the second order in one unknown function. These chapters lead logically to the development of the most important part of the subject with which the book is concerned, namely, the reduction of any system of equations to the canonical system of Riquier. The final chapter is devoted to systems in involution, in which another canonical form is considered. This is based upon M. Cartan's development of the Pfaffian system.

Numerous examples providing particular applications of the general theory are given. Many of these are followed by interesting analytical notes. Finally, valuable notes upon convergence of series solutions and the characteristic multiplicity of systems, together with a bibliographic summary for further reading, are given as an appendix.

Plane Trigonometry. By Prof. J. B. Rosenbach and Prof. E. A. Whitman. Pp. ix +216 . (New York: John Wiley and Sons, Inc.; London: Chapman and Hall, Ltd., 1929.) 10s. net.

THIs is, in general, quite a well-written book, though, in some respects, on old lines. It covers elementary trigonometry to the logarithmic solution of triangles, and makes a good beginning by defining the functions of angles of any magnitude with the aid of co-ordinates. Circular measure is also developed early and used frequently throughout the text. If, however, it is deemed necessary to devote a section to the theory and practical use of logarithms, there seems no reason for deferring such to the last chapter, especially when logarithms are freely used from Chapter ii. onwards. The section on the linear equation $a \cos \theta+b \sin \theta=c$ is not wholly satisfactory. Greater emphasis should be laid on the introduction of irrelevant roots by squaring than is given in Ex. 2 on p. 108. The method of transforming to a quadratic in $\tan \frac{1}{2} \theta$ does not seem to be dealt with.

There are plenty of good examples for which five-figure tables are required, but some of the calculations involved are unnecessarily heavy. The book is well printed, and answers to the examples are provided. 